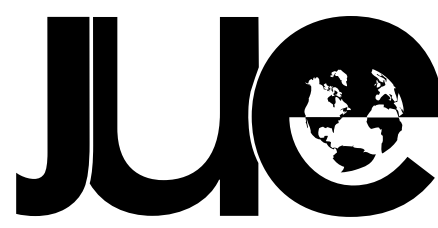

The Journal for Undergraduate Ethnography

Volume 2 | Issue 1

\title{
An Autoethnography of Fuencarral 43: Women in Masculine Public Space
}

\author{
Liz M. Rush \\ St. Louis University, MadRid, liz@LIZMRUSH.Com
}

\section{ABSTRACT}

n An Autoethnography of Fuencarral 43, semiotic analysis and feminist urban geography critiques are balanced with the use of autoethnography and personal narrative to present a study of women in public space. Through a feminist lens, a small plaza in the heart of Madrid, Spain is presented as a case representing the inequalities women experience through both architecture and the spatial ideology of urban geography, as well as through social conditions such as advertising, violence, and the privatization of public space. In addition to personal narrative, journaling and field notes are used as data sources along with participant observation and interviewing.

Keywords: autoethnography, Madrid, public space, feminism, urban geography 


\section{"It is not just that the spatial}

is socially constructed; the social is spatially

constructed too.

(Massey 1994, 6)

\section{INTRODUCTION}

Madrid's plaza de Fuencarral 43 is a curious space. It lies like an eddy in the current of pedestrians shopping on Calle Fuencarral, a street famous for its alternative vibe and location in a markedly hip part of the city. Unlike the many other spaces within Madrid's urban labyrinth, the open public square of Fuencarral remains without the title of "plaza" and is officially known as Fuencarral 43, which is simply the street address that spans the many shops and one home entrance. However, there are many other names that people use, including "Mercado de Fuencarral", which is actually the collectively owned group of expensive boutique lifestyle shopping stores that form one of the plaza walls. Another name that is sometimes used is "Plaza de Fuencarral", although you will never see that posted on a plaque in the traditional manner nor on any official documents. Thus when talking about the plaza, it is necessary to specify that it is the plaza space that is next to the Mercado de Fuencarral, often describing the franchise eateries that inhabit the space.

This autoethnography seeks to describe and recreate my experience of being a woman within this public space, which is a markedly masculine environment. Through the use of feminist urban geography critiques and semiotic analysis of the images within the plaza, this paper seeks to construct a full analysis of the ways in which gender is reinforced and defined by the cultural and physical structures within the plaza. It is considered a public space, but by analyzing the various ways that masculinity is acted out upon and dominates this space, it becomes evident that calling it a "public" area negates the very exclusion that women experience within Fuencarral 43. 


\section{"A vision of universal truth is really} just a dream of power over others... liberatory, emancipatory projects are better served by alternative knowledge production process." (Wall 2006, 3)

\section{LEGITIMIZING AUTOETHNOGRAPHY}

I chose to study Fuencarral 43 in a cultural research methods class, in which the students were asked to choose any one of the numerous plazas in Madrid. At first, this space did not stand out to me because it was so central to my everyday life. I lived close by and spent a lot of my social time in the neighborhood, and yet because it wasn't officially a "plaza" it didn't come to mind when I first set out to choose a plaza. Upon analyzing other plazas and public spaces, this apparent invisibility of this public space piqued my interest and I decided that the many layers of Fuencarral 43 would be a perfect subject. When I first began to study Fuencarral 43, I assumed that although I was experiencing the plaza, I would be able to prove or show the nature of the plaza through my analysis of observable, repeating events. I spent hours upon hours writing in my field log, and little by little the "I" began to pop up in my writing. I had also started keeping a personal journal around the same time, with the express purpose of documenting my recovery from a male-perpetrated rape. I mentally separated them into "Things I See" for the field log and "Things I Think" for the journal. After three months, I realized that I was no longer writing about Things I See or Things I Think, but that my writings had become indistinguishable from one another; saturated with "Things I Feel".

Feeling has never been in my vocabulary as a process of science, exploration, knowledge, or even truth. Despite a strong feminist background, I had indeed fallen into the trap that Andrea Dworkin describes in Woman Hating: "[O]ne can be excited about ideas without changing at all. [O]ne can think about ideas, talk about ideas, without changing at all. [P] eople are willing to think about many things. What people refuse to do, or are not permitted to do, or resist doing, is to change the way they think" (Dworkin 1974, 202). I have always known that "objective" science has an undeniable masculine and anti-woman bias, but I was unable to free myself from the idea that my feelings were invalid or unrelated in regards to my time in Fuencarral 43. They are not countable, measurable, repeatable, or even verifiable to an outsider, and yet I kept coming back to the way I felt in the plaza. I knew deep down that my feelings, even if "unrelated" as I was trained to believe, were legitimate. Upon recognizing this legitimacy, I realized that I was on my way to the most radical act I could imagine within science and society: refusing to silence a woman's (and in this case, my own) voice.

While I am aware of the critiques of the autoethnography and personal narrative, and will address them, I have never tired of the mantra "The personal is political" and believe it rings true. In this case, I might say that the personal is cultural since this work is about how Fuencarral represents, reflects, and reinforces cultural ideologies. I have no intention of denying the extremely personal nature of this work, but I also know that my experiences are not unique or aberrations from the norm. In An Autoethnography on Learning about Autoethnography, Wall argues that "those who complain that personal narratives emphasize a single, speaking subject fail to realize that no individual voice speaks apart from a societal framework of co-constructed meaning. There is a direct and inextricable link between the personal and the cultural" (Wall 2006, 9). I do not live in a vacuum removed from society and culture, and as such, I am situated to recount my experience. However, this is not merely a retelling of the time I spent in Fuencarral 43. I used my field $\log$ and personal journal as my data sets and also integrated other techniques of qualitative research. At times it became difficult to tell when I was "objectively" looking at some phenomenon within the plaza and when I was experiencing it. I began to question my ability to properly conduct research. When I looked at an advertisement of a woman, was I upset personally or was I upset because of what the analysis of that image evoked? Was there a significant difference? After writing the first draft of this paper, I realized that when I was excluding those personal feelings, I was excluding a major part of what it means to exist within and experience Fuencarral 43. As Ellis describes the autoethnography in Heartfelt Autoethnography, "Distinctions between the personal and cultural become blurred, sometimes beyond distinct recognition" (Ellis 1999, 673).

Other forms of research seek to present an analysis wherein the presence of the researcher is minimized or non-existent, as if one can study culture without experiencing and interpreting it. This façade of objectivity hides the interpretation and subjectivity that exists with all qualitative research. With the personal narrative, a falsified assertion of objectivity is rendered moot. In this autoethnography I seek to construct and evaluate my presence, rather than construct my absence.

Another critique of the autoethnography is that because it is personal, it is not verifiable and can't employ the traditional validity checks that other forms of qualitative researchers use. However validity can be checked through other means. In this personal narrative, I seek to recreate Fuencarral 43 in such a way that the experiences ring true to the reader. As Ellis puts it, "Validity means that our work seeks verisimilitude; it evokes in readers a feeling that the experience described is lifelike, believable and possible" (Ellis 1999, 674). I believe that upon reading my analysis, many will find that it inspires reflection of how their own experiences are related. 


\section{METHODS}

To research this project, I spent several months in the plaza spanning from January 2011 until May 2011. As previously mentioned, I kept a field log as well as a personal journal during this time, in which I wrote about not just what I saw but also the experiences of my use of Fuencarral 43. I also took several hundred photographs of the space and spoke to several of the employees of the plaza shops. I made sure to visit the plaza during different times and days in order to get a good feel of the various ways people occupy the space. Recent sexual violence lead to insomnia and social withdrawal which I thought would hinder my research but actually allowed me to experience the plaza with an unexpected dedication. Fuencarral 43 became my go-to site whenever I found myself struggling with my recovery. On average I would visit 4 to 5 times a week and would stay for two hours to specifically take notes and observe, however I often found myself visiting for pleasure and social gatherings. I patronized all of the establishments, both inside and on the terraces if available. I later went back to my field $\log$ and journal to categorize recurring themes and pick out experiences that were exemplary of common occurrences, as well as unique but potent events.

This analysis is divided into two sections. The first deals with the spatial realities of Fuencarral 43. Through the use of feminist urban geography critiques, the physical structures are analyzed to reveal the underlying ideologies behind the architecture. While the concept of space, especially public space, is social in nature, it is critical to look at the ways the physical realities reinforce gender relations. The inescapable nature of the actual space and architecture are necessary components of how people experience the plaza.

Second, this paper discusses the socio-psychological architecture of the plaza. Through analyzing the images that appear, as well as the people and interactions of Fuencarral 43, I emphasize how a psychological element is always present when discussing public space. I suggest the value of rejecting the romanticized Greek agora to understand how gender differences function within and also as a result of the sociopsychological structure.

By using autoethnography as a means to explore these two very different approaches to studying the plaza, I seek to understand how women are affected by these realities of public space. Thick descriptions of personal narrative are intertwined with the critiques of the physical space and the critiques of the social space in order to illustrate and draw conclusions about women within the specific context of Fuencarral 43 and extrapolate a new understanding about women in public space.

\section{“Contemporary feminist urban theory draws on post-structrualist ideas and theories of subjectivity, identity and meaning...Space is seen as fragmented, imploding, imaginative, subjective, unknowable and fantastic. Space is linked with power and difference."}

(Watson 2005, 101)

\section{FEMINIST URBAN GEOGRAPHY AND THE INVISIBILITY OF MASCULINE IDEOLOGY}

Early feminist work on urban studies focused on the spatial boundaries with regard to classic gender roles. The most well known example is that of the two spheres: the domestic/ feminine and the public/masculine. This simple binary reduces the complexity of space and architecture; however, it is not invalid. Fuencarral 43 is a public space through which many women move and occupy but the simple practice of using a space does not render it free of gender nor does it mean that the use of these spaces is free from inequalities. In this section, I analyze the architecture of the urban space in order to tease out the underlying ideology and uncover its ever-present, yet seemingly invisible, masculinity.

Introducing gender to architecture studies is relatively recent, however it would be naïve to think that gender was not a key player in how we design and conceptualize space. According to Sophie Watson in "Bodies, gender, cities," "Feminist perspectives on space have moved a long way from their early preoccupation with gendered forms of exclusion and marginality in the city. Over time these have become less and less located in simple binaries of public and private and home and work, and less and less analyzed in terms of a simple functionalism" (Waston 2005, 104).

Architecture is not just about constructions, but also a reflection of our ideologies. Jane Rendell argues that "radical practice should not only concentrate on solving problems in a practical way but also critique architecture as a form of representation consisting of images and writing...Architecture is no longer considered only in relation to the mode of production, but rather in relation to its reproduction through 


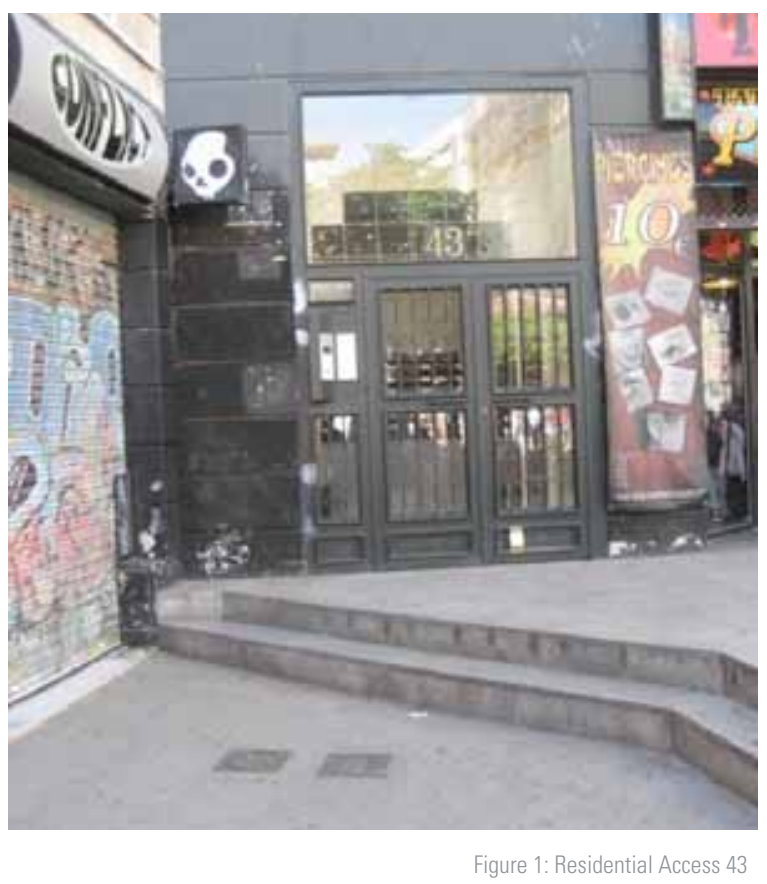

cultural representation, through consumption, appropriation and occupation" (Rendell 2000, 230). This is to say that we must not only analyze architecture and spatial arrangements for the physical inequalities and exclusions they create, but we must also take care to understand what those arrangements symbolize and how such symbols are implicated in the production and reproduction of unequal gender relations.

This is not to argue that function no longer holds an important spot in critiquing urban geography and it is perhaps the most evident example of ideology within Fuencarral 43. There is only one access to the residences, in the southwest corner of the plaza (Figure 1). It is designed in such a manner that access is severely restricted. By having stairs right in front of the door, people with limited mobility have a much harder time reaching the door. Anything with wheels must go around the stairs to a small ramp that is mostly blocked by the terraces of Lateral and Starbucks. This is problematic from a gendered perspective because women still shoulder the majority of domestic and child-rearing responsibilities.

Once I began researching the theories of feminist urban geography, I felt that the aspects of gendered space they described were very relatable however I couldn't quite pinpoint exactly what within Fuencarral 43 might make it a masculine space. My field log for the first few weeks in April of

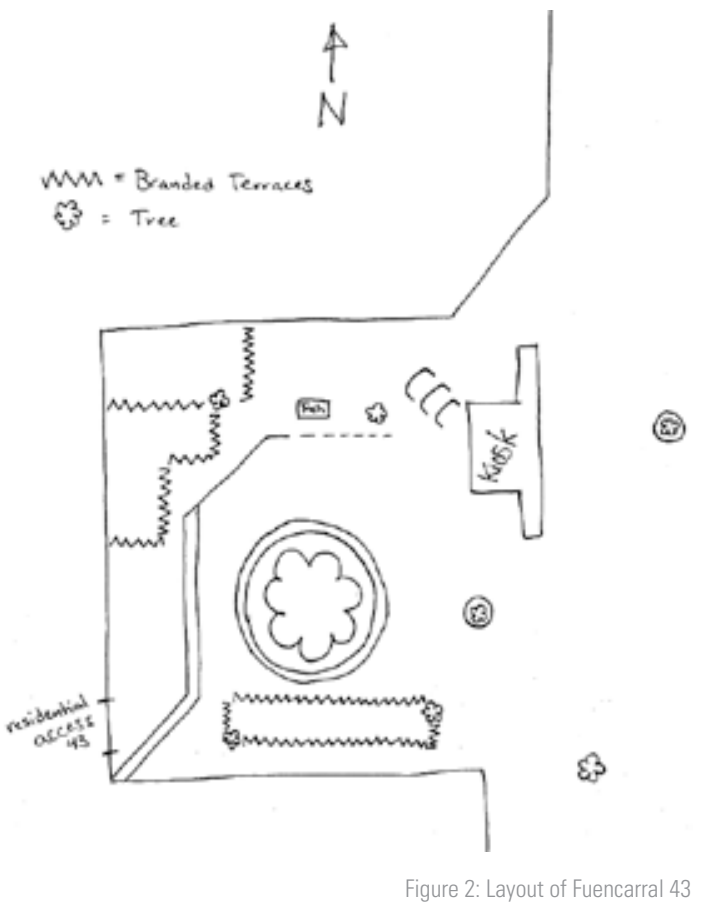

2011 were supposed to be filled with my notes of masculinity in the architecture, but it ended up being filled with doodles and observations such as, "This is sooo boring. What am I supposed to be seeing? If this masculinity is so invisible, how am I supposed to SEE it?" (Field log, April 13). The stairs to the residences were the first visible aspect to the ideology of the plaza that I was able to see clearly. The ramp access to the residences is marked by the dashed line (Figure 2), tucked away behind the kiosk and partially blocked by metal bars for locking up bicycles. Over the course of my time in the plaza, I only saw one instance of a man restricted by the stairs as he was bringing groceries to the door in a shopping cart. However, the number of women who were restricted was uncountable. Many domestic activities were limited because of the necessity of wheeled shopping carts and strollers. I began to treat this observation as a game, making little tick marks on a page of my field log that I divided into two columns: "Men who use the ramp" and "Women who use the ramp" (Field log, April 16). After a mere two days of being in the plaza, I had filled the "Women" column and decided that the game was too predictable to continue. In fact, on more than one occasion, when a heterosexual couple with a child would leave the residence, the man would take the direct route down the two stairs and wait for the woman to push the stroller 
around and down the ramp to meet back up with him. This example of limited mobility based on gendered domestic practices communicates to women, especially mothers, that their movements within Fuencarral 43 are counterintuitive, unnatural, and must be accommodated.

One of the most traditional definitions in architecture is the distinction between feminine and masculine constructions. In "Male space: architecture subtly reinforces gender stereotypes - not only for women, but for men", Joel Sanders argues, "In addition to spatial boundaries, architecture employs other formal means to shape masculinity - by identifying manliness as "genuine" and womanliness as "artifice," architects since Vitruvius have associated the ornamented surface with femininity, not masculinity" (Sanders 1996, 77). Decoration is seen as an embellishment, or in other words, unnecessary. Because these feminine attributes of design are considered superfluous, they reflect the values a culture places on femininity. These embellishments are considered less valuable, and this attitude reflects cultural ideologies about women as superfluous and less valuable, or serving as decoration and accentuation to the masculine environment.

From the selection of the classic unadorned columns as "masculine" to the obsession with functionality in minimalist architectural works, masculinity in architecture is a construct that has been normalized into invisibility. It is not innate to the way space is developed, but because of the saturation of masculinity in Western architecture, this ideology remains hidden by sheer volume and exposure. Using Le Corbusier as a prime example of modernist architecture, the masculine is meticulously created through the minimization of decoration. As Mark Wigley points out in his analysis of modernist architecture "White-out: Fashioning the Modern [Part 2]", masculinity can be found in "the thin coats of whitewash painted on the pristine walls of modern buildings and associated with such 'masculine' traits as logic, hygiene, and truth. Despite its apparent invisibility, this whitewash functions as a layer added to the surface of buildings" (Wigley 1993, 11). This example highlights just one of the ways the masculine in architecture and urban studies is attributed to and forms part of so-called "neutral" spaces.
Sanders goes on to examine the Air Force Academy in Colorado Springs as a prime example of the way the masculine is constructed: "More often than not architects fabricate masculine environments by seeming to undress building surfaces: less is more masculine" (Sanders 1996, 79). The building is free from any "softness" or superfluous decoration in an attempt to communicate and reinforce the ideologies of masculinity and imbue them in the cadets. He describes the building as "conspicuously lacking in detail, obeying a logic of absence, or austerity - a logic implicitly predicated on the eradication of 'feminine' excess or ornamentation" and that these characteristics, from the clean lines to the pure functionality of the building, "represent a masculinity that pretends to be natural, but is in fact consciously produced through carefully conceived environments" (Sanders 1996, 80).

The materials used in constructing the plaza are markedly masculine. It is constructed entirely of angular stones, with no embellishments whatsoever. Masculine environments are created not just through the design and arrangement of space, but through the very materials from which the architecture is derived. As Sanders explains, "Materials are made to bear the weight of all the cultural values that masculinity purportedly connotes... Because of their hardness, durability, and strength, materials such as glass, steel, and stone are ascribed masculine properties" (Sanders 1996, 78). Like Sanders's description the Air Force Academy, Fuencarral 43 consists of "undressed" forms. The cold, severe lines of the stone constructions communicate a minimalist, or masculine, ideology. The plaza is obsessively free of adornment (aside from branded installations that are added by the eateries that inhabit it) to such an extent that any marking of femininity is excluded. Nature is often associated with femininity, and the only significant plant life consists of a few trees that are encircled by cement markers and are virtually inaccessible.

This produced masculinity within architecture is so prominent that it often goes unnoticed or is considered an organic form of art, removed from the cultural ideologies about gender. However, recent developments in feminist urban geography and critiques of architecture demonstrate that these environments are highly developed reflections and reinforcements of gender differences. 


\section{Space is not merely a surface where social practice takes place. Rather, space is produced in social practices; it is a social category in itself. Space is simultaneously the medium and the outcome of social practices.}

(Watson 2005, 101)

\section{SOCIO-PSYCHOLOGICALARCHITECTURE OFTHE PLAZA}

To speak only of the physical masculine properties of the Fuencarral 43 plaza would be a frivolous attempt to divorce the space from experience of culture. I've chosen the phrase "socio-psychological architecture" because women's interactions with space, especially public space, are colored by many factors that create a masculine environment of not just external interactions with the space and its inhabitants, but also the internal psychological and emotional realities women face within the space. There are many in-depth studies describing each of these phenomena individually, but my focus is to touch on several different things that take place in Fuencarral 43. I will illustrate how an abundance of misogynistic advertising cannot be separated from street harassment or from violence against women in public and in private. All of these factors operate together, in an organized system, to affect women in the plaza of Fuencarral 43. In my conception of socio-psychological architecture, "architecture" is the key word; chosen to remind that the social and cultural practices that form ideas about space are constructed and not innate. The word architecture deliberately invokes an image of an elaborate, purposeful, structured system with interdependencies. The physical structures that are created, called architecture, and deemed neutral despite evidence to the contrary are analogous to the socio-psychological structures that affect and reinforce gender differences. It is important to note that these socio-psychological structures are not independent of and separate from one another, but rather this analysis will focus on several key characteristics in order to illustrate the overarching ideology of the structured system.

\section{ADVERTISING}

When Catherine McKinnon developed the earliest definitions of sexual harassment, it was in response to the growing numbers of women in the workplace being exposed to degrading images of women. McKinnon argued that because the women are captive audiences in the workplace, these images have a distinct function. Not only do they serve to please a voyeuristic male gaze, but they also reiterate to women their status as less-than-equals. Sexual harassment laws are now in place in an attempt to create more egalitarian work places; however, the same analysis can be applied to outdoor advertising. As Rosewarne argues in "Pin-ups in public space: Sexual outdoor advertising as sexual harassment," "In the workplace for example, pin-ups are deemed problematic because employees are held 'captive' to them in that their exposure is made unavoidable. This exact same situation is played out in the outdoors: A commuter cannot avoid seeing a sexist billboard" (Rosewarne 2007, 314). The public nature of the plaza means that the only way to avoid exposure to offensive material is to self-exclude.

Advertising does not exclusively portray women, but all too often sex and violence in advertising are euphemisms for women and violence against women in advertising. Rosewarne argues in "The Men's Gallery Outdoor advertising and public space: Gender, fear, and feminism":

"The sheer number of women portrayed in outdoor advertising far outweighs men, and therefore on a cursory level, advertising can be interpreted as contributing to the gendering of public space through its continued use of women as "artifice". When women are relegated to the background - as artifice, as decoration - it is evident that the masculine nature of public space has placed limitations on their inclusion. The negative, disempowering effect of this kind of objectification extends beyond the "ornamented surface" and can be interpreted as having harmful ramifications on the mental and physical safety and prosperity of all women in public space." (Rosewarne 2005, 70)

The manner in which women are portrayed in outdoor advertising, as sexualized decoration, is distinct from the manner in which men are often portrayed. Men's presence is generally used to give authority to a product, while women's bodies are used as adornment (Rosewarne 2005, 71). The use of women's bodies in advertising communicates the belief that a woman's primary role is as sexual ornamentation. This highly sexualized imagery reminds women of their status in society and due to the public nature of these advertisements, they cannot be avoided. Women, in this sense, are a "captive audience" upon each venture out into public space. 


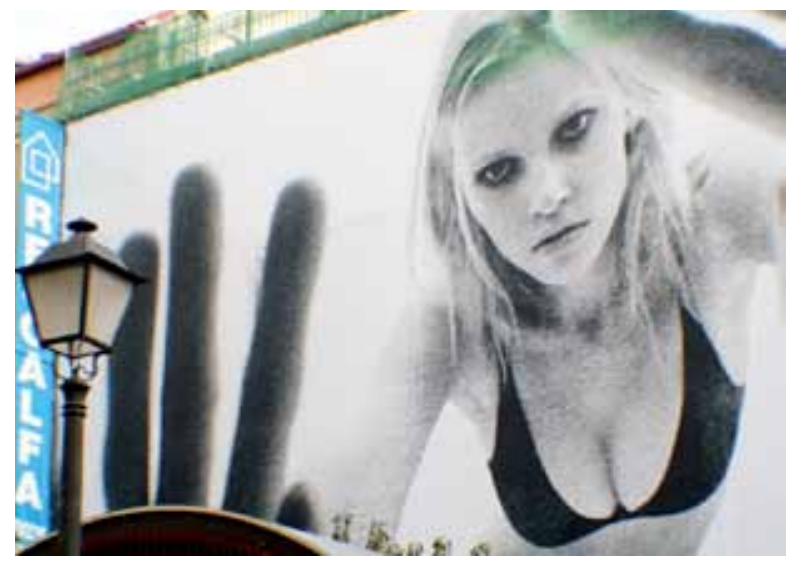

Figure 3: CK ad in Fuencarral 43 (March 2011]

The above Calvin Klein ad (Figure 3) was replaced by this Tommy Hilfiger ad (Figure 4) on a façade in Fuencarral 43, where both have loomed over the plaza. The man in the second ad is not sexualized and the layout even includes text with his name and occupation. His presence is there to lend a voice of authority and endorsement to the product. On the other hand, the woman is nameless and has no context. Rosewarne expands this idea by comparing images of women in advertising in Australia to the classic pin-up images of women from the 1950s. One of the important themes in the pin-up is the removal of "distractions" from the image. The woman's body is a "free-floating" non-entity (Rosewarne 2007, 318). Without reference to personality, identity, or individuality, the woman represents all women.

Dworkin expands on what the aesthetic of the pin-up means in her piece Vargas' Blonde Sambos. These images, especially of white women upon white backgrounds, push the "boundaries of nonexistence ... there [is] no fat because there is no flesh" (Dworkin 2000). We can see the blurring between the distinction of background (nothingness) and body (woman). By blurring these lines, the represented woman becomes a non-entity. Rosewarne argues that the pin-up aesthetic equates "woman" with "absence": without reference to anything but the body, and even then erasing the distinction between body and nothing, the image represents a lack of intellect, a lack of challenge, and a removal of distractions from the woman's primary role - to instigate sexual arousal (Rosewarne 2007, 318).

Within this Calvin Klein ad, the aesthetic is clearly one of violence. The defensive position, the nudity, the darkened eyes and tousled hair all point to the mainstreaming of sexualized violence against women in the media. It is a prime example of Dworkin's analysis of the pin-up aesthetic.

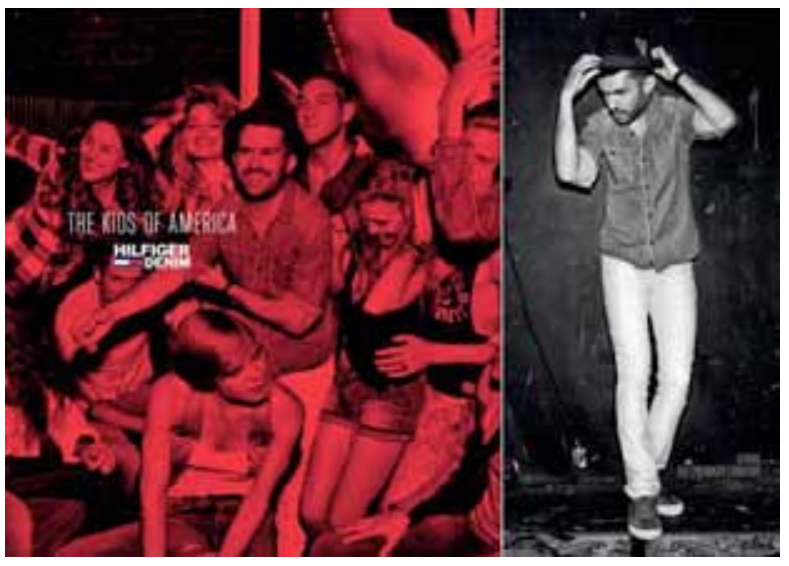

Figure 4: TH ad (April 2011)

The only part of her body that is defined in contrast to the background of nothingness is her breasts, drawing the eye to focus on the part of her that "exists" in comparison to her white body that melts into the background. These violent images in public mark the plaza as a highly masculinized space. "Just as the pin-up excites the soldier and reinforces his masculinity, the sexist advertisement can be understood to excite the male passers-by, marking the space as a male domain" (Rosewarne 2007, 321).

Before starting this project, I had previously patronized the tattoo and piercing studio within Fuencarral 43 and had met many of the workers of the studio, including a friendly piercer. We struck up a friendship and he introduced me to several of the other workers in Fuencarral 43 and gave me an in with the workers of the skate shop, restaurant, and Starbucks. One night we agreed to meet up at the plaza when the sudio closed, and when I arrived I stood around waiting for him to lock up the studio. It was the first time I looked up and saw the previously mentioned Calvin Klein ad. I immediately took out my field log and started writing:

\section{CK ad Fuencarral 43:}

- White, blond woman in defensive position

- Looks like a battered woman

- Breasts as focus

- No product in the ad

- Sexxay ${ }^{1}$, sexxay violence" (Field log, March 14) 
When the piercer, ALM, asked me what I was writing about, I showed him my notes and told him that I was really uncomfortable. He told me to not take it "so personally" and that the woman in the ad had nothing to do with me. I explained to him that actually, yes, she did, and later wrote about our conversation in my journal:

Seriously though, how can men not see that ads which have sexxay violence against women are problematic? I told ALM that I was violently raped in January and that seeing those images makes me think about things that happened to me. He was all, 'Well, you know, you have to deal with your own problems and not think of this as related. The ad has nothing to do with what happened to you'. Really, ALM? You're sure that your diet of pornified violence and violent porn has nothing to do with what's acted out against me/millions of other women? It's not like I'm the only one (or that it's happened just once, for Christ's sake). Plus, does it fucking matter if that picture has anything to do with me personally? Shouldn't the fact that it makes me feel physically ill when I look at it be enough to warrant some sort of change? Ugh, this kind of shit makes me want to not go outside ever. I can't avoid it and it's not fair.

(Journal, March 15)

When reading the images of the plaza, I came to realize that not including this voice and reaction was inherently an omission of one of the aspects of experiencing the plaza. And yet, even at this point I was still struggling to recognize that this was a valid part of my research. When I spoke with my peers who were also studying plazas in Madrid, time after time we would end up discussing these parts of what it means to be in public space. Many of my female peers were enthusiastic about sharing similar misogynistic propaganda within their plazas, and yet none of us were including this in how we read the plaza as "public space". During one of our small group discussions, one peer told me that I wasn't being objective enough because of my history of sexual violence. I asked her, "But if it's something like one in four college-aged women have been victims of sexual violence, isn't it actually anti-woman bias to omit those voices?" (Journal, April 2). The pieces of this project were beginning to fall into place.

\section{VIOLENCE AND FEAR IN PUBLIC SPACE}

Violence in public space is not just relegated to representations through media and advertising. Fear of violence against women creates gendered exclusions in the plaza. Despite the fact that most violence against women is perpetrated domestically, fear of violence in public dramatically alters the way women inhabit public space. According to Koskela in "Gendered Exclusions: Womens fear of violence and changing relations to space," "Urban space is produced by gender relations, and reproduced in those everyday practices where women do not - or dare not - have a choice over their own spatial behaviour. Experienced violence, threat of violence, sexual harassment and other events that increase a woman's sense of vulnerability are reinforcing masculine domination over space" (Koskela 1999, 112).

Koskela asserts that use of space is often considered on an individual basis. That is, because of such a strong ideology of individuality, we consider our actions in public space to be seen as free choices, despite the fact that they are products of social power relations (Koskela 1999, 112). "Because of fear, women are restricting their access to and activity within public space. Collectively, women constitute an example par excellence of the unequal victim because they are socially and physically vulnerable to victimization" (Koskela 1999, 113). It is important to note that while men can also be victims of violence, women as a social class are far more likely to be victimized and fearful of violence in both private and public. Of course, domestic and public violence cannot be separated spatially. Addressing women as a class of victims in a violent culture, Koskela argues that "there is no separation of the dimensions of fear. A culture of domestic violence in private leads to fear across all spatial boundaries" (Koskela 1999, 112).

The culture of domestic violence ties back into advertising in public spaces. The issue of whether one fuels the other is outside the scope of this project, though is it certain that violent imagery feeds women's fear of violence. As Rosewarne argues in "The Men's Gallery," “The issue of fear of attack is two-fold: (i) there is the understanding that the potential would-be criminal comes to view ordinary women as subordinate based on their media diet of sexually objectified women; and (ii) there is the understanding that women come to see themselves as bestowed with female sexuality above all else" (Rosewarne 2005, 73). Relating this to women's exclusion in masculine public space, Rosewarne asserts, "This exclusion stems from highly sexualized imagery reminding them of their sexual vulnerability that, in turn, has them fearful for their safety and alters their behavior to compensate" (Rosewarne 2005, 68). 
Despite the many hours I spent in Fuencarral 43 over the course of several months, I have never become completely comfortable in that space. I would dread leaving the comfort of my apartment, as is exemplified by this journal entry: "I should go to Fuencarral today, and I know I should force myself, but I just want to be left alone and every time I go out there some guy tries to talk to me. It doesn't matter if I'm writing and have my big headphones on, some dude invariably feels the need to talk to me and invade my time and space." (Journal, April 2)

In mid-April I came to realize that these entries in my journal highlighted a very important aspect of what it means to be a woman in public space. I had decided this year that I would stop being silent about sexual violence and rape in my life, especially around men. The more I talked about it, the more I heard men tell me that they had never met another rape victim before. I find this impossible to believe. Unsurprisingly, the more I talked about it with women, the more I heard about their victimhood. I learned about painful amounts of sexual violence that my peers had experienced and that many of them also felt the same way I did when seeing these types of advertisements. It wasn't until I was rereading my field log and realized that these common experiences are integral to understanding Fuencarral 43:

So I had coffee with a friend in Fuencarral today. Some guy who looked to be about 30 came up to us in the terrace and just stood there and said "guapaaaaas" 2. After he left, she seemed to laugh a bit nervously, but I was not having any of it. I said, "The fuck was that?" and she told me how much she hated it when men cat-called at her. It was a relief to hear that it bothers her too. It's obviously not about sex because they know they aren't going to get sex by doing those things. It's about control, dominance, and power. It's like they want us to know that they are judging us constantly, every time we go out in public.

(Field log, April 7)

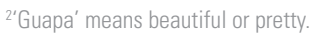

Koskela argues, "Violence inflicted on a woman by one particular man becomes fear of violence from any man. This fear of any man in the street turns space into a highly masculine field" (Koskela 1999, 116). This passage struck me with such force that I suddenly felt a wave of nausea. I realized that I had omitted, perhaps out of denial or selfprotection, experiences that made the first two months of my research extremely difficult. I never wrote these feelings down because they were fleeting, painful, and above all, something I didn't want to be subjected to. These feelings came from a rape in the January before starting this research: an abusive ex-partner caught a plane to Madrid and showed up at my door without warning. He forced his way into my home in order to coerce me to return to the relationship and failing that, rape me.

On many occasions, I would sit in Fuencarral 43 and catch a split-second glimpse of a person who had similar features as the man who raped me. In that fraction of a second, my heartbeat would dramatically speed up and I would freeze. Despite all the rational thoughts I had at my disposal to calm myself down and realize that I was not in immediate danger, those small moments of panic added up to quite a bit of time. While my rape did not take place in public, the fear and culture of violence is not bound to the physical location in which it took place. To repeat Koskela, "There is no separation of the dimensions of fear. A culture of domestic violence in private leads to fear across all spatial boundaries" (Koskela 199, 112).

\section{PRIVATIZATION OF THE PUBLIC}

A critique of plaza Fuencarral 43 would not be complete without a mention of privatization. My initial plans for studying this plaza revolved around the privatization and advertising within the public space because it seemed curious to me that the plaza was well known for the Mercado de Fuencarral, a high-end alternative fashion shopping center, and its franchise eateries such as Starbucks and Lateral. However, upon researching privatization critiques, I came to "Introducing Gender to the Critique of Privatized Public Space" by Kristin Day, which brought to light the issues regarding gender within privatization and anti-consumerism discourse. 
Day argues that privatization critiques by and large ignore gender all together, and yet at the same time reinforce negative stereotypes of women and femininity:

The prevailing critique of the privatized space is, in some ways, a critique of the supposed 'feminization' of public space. Passive participation, consumption and fear these characteristics have been attributed to women's use of public space... the characterization of consumption and other supposed ills of public life as "feminine" is problematic. In reality, consumption, passivity and fear - negative attributes ascribed to modern public life - are often particularly constraining for women. These shortcomings are better understood not as pathologies emanating from women, but as impediments to women's participation in public space. (Day 1999, 174)

The plaza of Fuencarral 43 is linked with conspicuous leisure, with three private terraces that take up most of the public space. The street Fuencarral is itself known for its alternative, yet upper-class retail stores. It features wellknown brand names from within Spain and worldwide. I was originally drawn to critiques of the consumerism of this public space because it was rare to see anyone enjoying the space without having some sort of shopping bag or take-away cup with them from one of the nearby shops. Most of the clothing shops on Fuencarral are targeted towards women, with the exception of a few skate shops. High-end makeup stores, such as MAC, feature prominently on the paths towards the plaza. However, as Day discusses, analyzing such spaces without taking into consideration the impact of and upon gender is "to tell only half the story. Many privatized spaces reproduce gender oppression by reinforcing the association of women with frivolous, status-oriented consumption... Beyond the obvious emptiness in a public life focused on buying and owning, spaces that reinforce women's engagement in frivolous consumption marginalize women and trivialize their role in public life" (Day 1999, 168).

Privatization critiques that ignore gendered exclusions and reinforce associations of femininity with shopping, consumerism, and conspicuous leisure have anti-woman ideology at their heart. None of these things is inherent within women, but are social constructs of femininity. In fact, they cause women a double-bind: by associating consumerism with women, they become trained to take part in harmful practices and yet also oblige women to use this formulation of femininity as a primary form of identity construction. As Day points out, "Ubiquitous store windows and mannequins are common sites of female identity construction, first making women dissatisfied with their own appearances, and then promising more perfect figures and faces, attainable with the right commodities. Though specific projected images may change, even dramatically, the focus on beauty and its basis in consumption remain the same. Women's use of such spaces often fuels dissatisfaction with themselves... Privatized public spaces often market women's sexuality for consumption, thus constraining women through sexual objectification" (Day 1999, 169). Fuencarral 43 is not exempt from this practice that limits women; in fact, despite its status as an "alternative" scene, the focus on consumption as means to obtaining and maintaining status as a woman is central.

The advertisement for the Mercado de Fuencarral and Beefeater (Figure 5) is a prime example of using consumption to define women's sexuality. Although the woman portrayed is covered in tattoos, the basic beauty ideals are present: skinny, white, submissive, and without context. The ad copy is also problematic. It reads, "What happens in the changing rooms will be our secret". Of course, the problem is two-fold: that of associating women's sexuality with clothes shopping and that of the underlying threat of secrecy regarding sex and women - secrecy that could potentially include the sexual violence evoked in the surrounding ads.

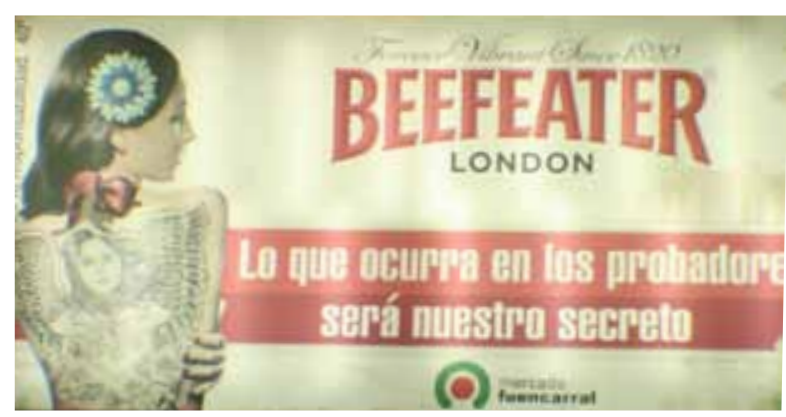

Figure 5: Mercado de Fuencarral Ad 


\section{"Space is organized in ways that} reproduce gender differences in power and privilege. Status is embedded in the spatial arrangements, so that changing space potentially changes the status hierarchy and changing status potentially changes spatial institutions. "

\section{CONCLUSION}

My goal in this autoethnography was to document not just the theoretical aspects of how gender functions in the plaza, but also to give voice to the experience of being a woman within this public space. Because the research and writing itself have taken me in all different directions, upon reflecting about Fuencarral 43 my biggest disappointment is not being able to continue and go more in depth with the topic. My experiences have lined up with the theory reviewed in this paper, but I believe it is necessary to further study the ways in which gender is reflected and reinforced in this specific public space. I would have like to have conducted interviews with other women, especially women who are victims of recent sexual violence or rape, in order to see to what extent they identify with the experiences I've presented here. I believe that it is not only necessary to study how women recount their personal experiences of public life in relation to gender and power, but also to urge them to give themselves voices and to tell their stories in their own words.

Despite the overwhelming evidence that Fuencarral 43 is a masculine space, I would in no way consider or suggest avoiding it. As Weisman writes in Discrimination by Design, "The denial of women's rights as citizens to equal access to public space- and of the psychological and physical freedom to use it in safetyhas made public space, not infrequently, the testing ground of challenges to male authority and power" (Weisman 1994, 79). That is to say, although women are victimized by masculine public space, that very space can be where women dismantle the anti-woman ideology in the built environment, refuse to accept an exclusionary status in masculine spaces, and assert our right to a truly inclusive public space. This researcher, for one, plans to do just that.

\section{ACKNOWLEDGEMENTS}

I would like to thank Dr. Erika Polson for the indispensable guidance and encouragement. I also thank Katie Wilson and Laurel Long for the validation and support over the course of this project. Finally, I would like to thank the reviewers and editors of the JUE. 


\section{WORKS CITED}

Bondi, Liz and Damaris Rose. "Constructing Gender, Constructing the Urban: a review of AngloAmerican feminist urban geography". Gender, Place and Culture, 10, no. 3 (Sept. 2003): 229 245.

Day, Kristen. "Introducing Gender to the Critique of Privatized Public Space". Journal of Urban Design, 4, no. 2 (1999): $155-178$.

Dworkin, Andrea. Vargas' Blonde Sambos. 2000. http://www.nostatusquo.com/ACLU/dworkin/ vargas.html

Dworkin, Andrea. Woman Hating (Plume, 1974): 202.

Ellis, Carolyn. “Heartfelt autoethnography”. Qualitative Health Research, 9 (1999), 669 - 682.

Koskela, Hille. "Gendered Exclusions: Women's fear of violence and changing relations to space". Geografiska Annaler., Human Geography, 81, B2 (Blackwell Publishing on behalf of the Swedish Society for Anthropology and Geography, 1999): 111-124. http://www.jstor.org/ stable/491020

Massey, Doreen. Space, Place, and Gender (University of Minnesota Press, 1994), 6.

No author. "Hilfiger Denim Spring/Summer 2011 Campaign- The Kids of America". http://www. labdailyblog.com/?p=17321

Rendell, Jane. Gender, Space, Architecture: An Interdisciplinary Introduction (London and New York: Routledge, 2000): $230-235$.

Rosewarne, Lauren. "Pin-ups in public space: Sexual outdoor advertising as sexual harassment". Women's Studies International Forum, 30, 4 (University of Melbourne, July-August 2007): 313 - 325.

Rosewarne, Lauren. “The Men's Gallery: Outdoor advertising and public space: Gender, fear, and feminism". Women's Studies International Forum, 28, 1 (University of Melbourne, JanuaryFebruary 2005): $67-78$.

Sanders, Joel. "Male space: architecture subtly reinforces gender stereotypes - not only for women, but for men". Architecture, 85, no. 6 (June 1996): 77 - 81.

Spain, Daphine. Gendered Spaces (The University of North Carolina Press, 1992): 30 -233.

Wall, Sarah. "An Autoethnography on Learning about Autoethnography". International Journal of Qualitative Methods, 5, no. 2 (June 2006): 1 - 12.

Watson, Sophie. "Bodies, gender, cities". City: Analysis of Urban Trends, Culture, Theory, Policy, Action, 4, no. 1 (2005): 101-105.

This work is licensed under a Creative

Commons AttributionNonCommercialNoDerivs 3.0 Unported License.

Weisman, Leslie. Discrimination by Design: A Feminist Critique of the Man-Made Environment (University of Illinois Press, 1994): $67-87$.

Wigley, Mark. "White-out: Fashioning the Modern [Part 2]". Assemblage, 22 (MIT Press: Dec. 1993): 6 - 49. Stable URL: http://www.jstor.org/stable/3171168 